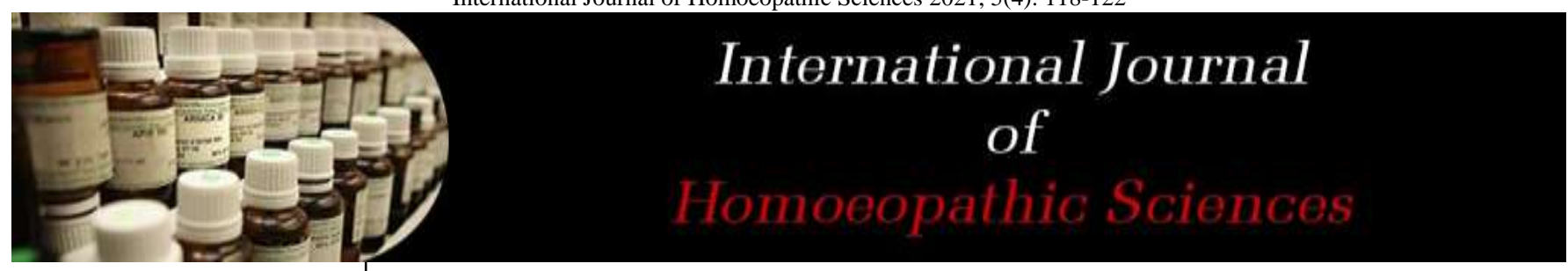

E-ISSN: $2616-4493$ P-ISSN: 2616-4485 www.homoeopathicjournal.com IJHS 2021; 5(4): 118-122 Received: 13-08-2021 Accepted: 17-09-2021

Dr. R Sitharthan

a) Professor \& HOD,

Department of Practice of

Medicine\& Research Guide,

National Homoeopathy

Research Institute in Mental Health (NHRIMH)

Kottayam. Kerala, India

b) Former Professor \& HOD in

Practice of Medicine \& Research Guide, Vinayaka Missions Homoeopathic Medical College, Salem. Tamil Nadu, India

Dr. Hafsa Muhammed BHMS, Post Graduate Traniee, III MD(Hom), Department of Practice of Medicine, National Homoeopathy Research Institute in Mental Health (NHRIMH), Kottayam. Kerala, India

Dr. Nilina PR

BHMS, Post Graduate

Traniee, III MD(Hom), Department of Practice of Medicine, National Homoeopathy Research Institute in Mental Health (NHRIMH), Kottayam. Kerala, India
Corresponding Author: Dr. R Sitharthan

a) Professor \& HOD,

Department of Practice of Medicine\& Research Guide, National Homoeopathy Research Institute in Mental Health (NHRIMH), Kottayam. Kerala, India b) Former Professor \& HOD in Practice of Medicine \& Research Guide, Vinayaka Missions Homoeopathic Medical College, Salem. Tamil Nadu, India

\section{Management of lower urinary tract symptoms in benign prostatic hyperplasia with individualised homoeopathic medicines: Case reports}

\author{
Dr. R Sitharthan, Dr. Hafsa Muhammed and Dr. Nilina PR
}

DOI: https://doi.org/10.33545/26164485.2021.v5.i4b.460

\begin{abstract}
Benign prostatic hyperplasia (BPH) is a common condition in elderly men and has a significant impact on their quality of life. Surgical procedures in the management of BPH have been associated with more adverse effects on patients. This retrospective study aims at management of BPH symptomatically by using the International Prostatic Symptom Score (IPSS). The article comprises three cases of BPH where there was considerable alleviation of symptoms following homoeopathic intervention.
\end{abstract}

Keywords: Homoeopathic medicines, Benign prostatic hyperplasia, International Prostatic Symptom Score (IPSS)

\section{Introduction}

Benign prostatic hyperplasia/hypertrophy $(\mathrm{BPH})$ is a condition characterized by nonmalignant growth of the prostate observed commonly among aging men significantly impacting their lives. BPH, the actual hyperplasia of the prostate gland, develops as a strictly age-related event in most men, starting at approximately 40 years of age. Several studies have been investigated into the histologist prevalence of $\mathrm{BPH}$ and it was found that approximately $10 \%$ for men in their $30 \mathrm{~s}$, $20 \%$ for men in their 40 s, reaches $50 \%$ to $60 \%$ for men in their $60 \mathrm{~s}$, and is $80 \%$ to $90 \%$ for men in their $70 \mathrm{~s}$ and $80 \mathrm{~s}^{[1]}$. The condition becomes clinically entitled when it happens to be associated with subjective symptoms, like lower urinary tract symptoms (LUTS). Microscopic evidence of BPH shows prostatic stromal and epithelial hyperplasia and the macroscopic BPH represents the enlarged prostate. This prostatic proliferation occurs exclusively in the transition zone and periurethral glands ${ }^{[2]}$ In spite of many decades of vigorous and intense research, the entire causation evolving around BPH is still poorly understood. Among all the dominant hypotheses, the hormonal or dihydrotestosterone (DHT) hypothesis is most often invoked. Often a positive family history also becomes a risk factor. Researches in several aspects, could not conclusively link the development of BPH especially to smoking, obesity, and sexual activity or their lack [3]. Asian Indians who are found to be vegetarian and consume low fat and high-fibre diets, contains low amount of phytoestrogens and are suggested to be chemopreventive agent for the genesis of $\mathrm{BPH}^{[4]}$. BPH in itself might not cause any problem and the bothersome LUTS can meddle with daily living, causing significant impairment of the disease-specific quality of life, and interfere with sexual functioning ${ }^{[3]}$.

There is no concordance established showcasing the degree of prostate enlargement required to support the diagnosis of BPH. Clinically, BPH presents the clinical manifestations that are attributed to the enlarged prostate. This includes the lower urinary tract symptoms (LUTS), bladder outlet obstruction, incomplete bladder emptying, acute and chronic urinary retention, urinary tract infection (UTI), urosepsis, bladder stones, and hematuria ${ }^{[5]}$. LUTS symptom complex can be appreciably divided into obstructive and irritative symptoms. Obstructive symptoms include hesitancy, straining, weak flow, prolonged period of voiding, partial or complete urinary retention, and, ultimately, overflow incontinence. The more bothersome irritative symptoms are frequency, urgency with incontinence, nocturia, dysuria, as well as small voided volumes which happen to affect the Quality of life (QoL) of the individual ${ }^{[6]}$. Several studies have shown that complementary medication therapies do play an effective role in controlling early prostatic hypertrophy ${ }^{[7-10]}$. It also happens that men are reluctant to opt for surgical interventions for fear of losing their potency and the cognizance of other adverse side effects. 
Among complimentary system, homoeopathy plays a magnificent role for the alleviation of ailments. Several homoeopathic interventional studies on enlarged prostate found marked improvement in urinary symptoms of BPH patients ${ }^{[11-14]}$.

Diagnosis and assessment of BPH relies mostly on subjective patient reporting apart from USG. This subjective dependency for the elaboration of symptoms in men with LUTS demands a need for developing a symptom scoring system that can be used and reproduced to evaluate symptoms and hence can help to guide management strategies. One such scoring system is the International Prostate Symptom Score (IPSS). The IPSS was designed to be an easy, self-administered questionnaire which can be used even in primary health care clinics.The first version of IPSS was created by the American Urological Association (AUA) and consisted of seven questions and was named as AUA symptom index (AUA) or AUA-7. It was later endorsed by the World Health Organization as the IPSS. Evaluation of questionnaire consist of a combination of urinary storage and voiding symptoms, allowing the patient to choose 1 of 6 answers indicating increasing severity of the particular symptom. The scoring was assigned points from 0 to 5 . The total score ranges from 0 to 35 (asymptomatic to very symptomatic). Additional $8^{\text {th }}$ Question on QoL was added later on. It helps convert subjective symptoms into objective numbers that can be further quantified ${ }^{[15]}$.

\section{Materials and Methods}

This retrospective study was done at the Practice of Medicine OPD unit of National Homoeopathic Research Institute in Mental Health, Kottayam. Three diagnosed cases of BPH were taken to consider the significant improvement in their condition post interventionally. Also the change in their QoL was considered for assessment. Assessment of symptomatology was done using before and after IPSS score. Follow-ups were considered for a period of 1 year.

\section{Case Information \\ Case 1}

Patient aged 67 years complained of obstruction to flow of urine since 2 years. He was often catheterized when the complaint was acute. The complaints occurred every year in same time. Now he has obstruction with burning pain on micturition, frequency with weak stream aggravated at night. Prostate specific antigen (PSA) was 4.6. In ultrasound (USG) there was moderate prostatomegaly. He had past history of dyspnoea on exposure to cold climate. No relevant past history. He had desire for sweets, urgency with frequent desire for evacuation, passes 3-4 times daily. He had a habit of smoking since 15 years.

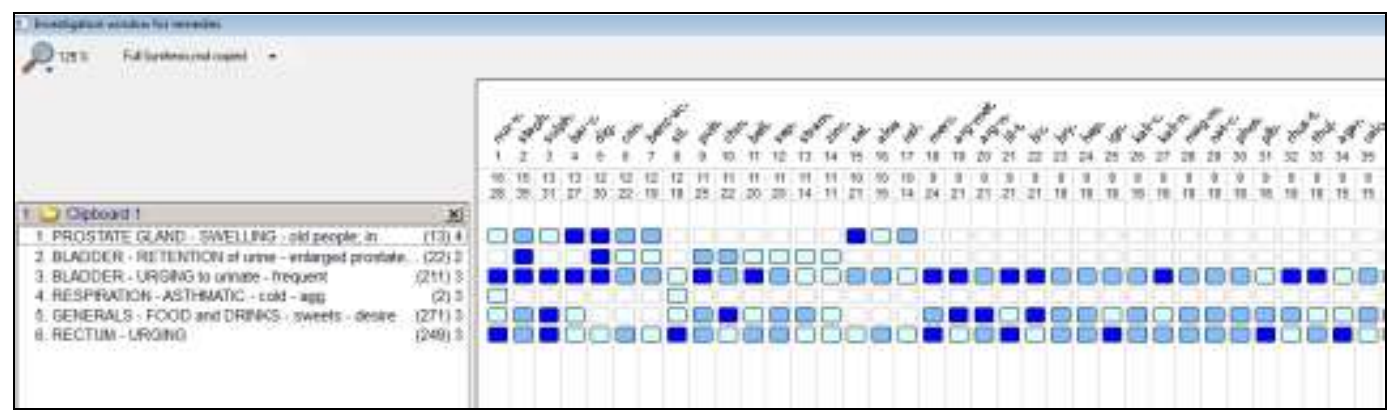

Fig 1: Repertory chart (Case No:1)

He was prescribed Nux Vom 200/once in a week, according to the reportorial totality (Figure1).

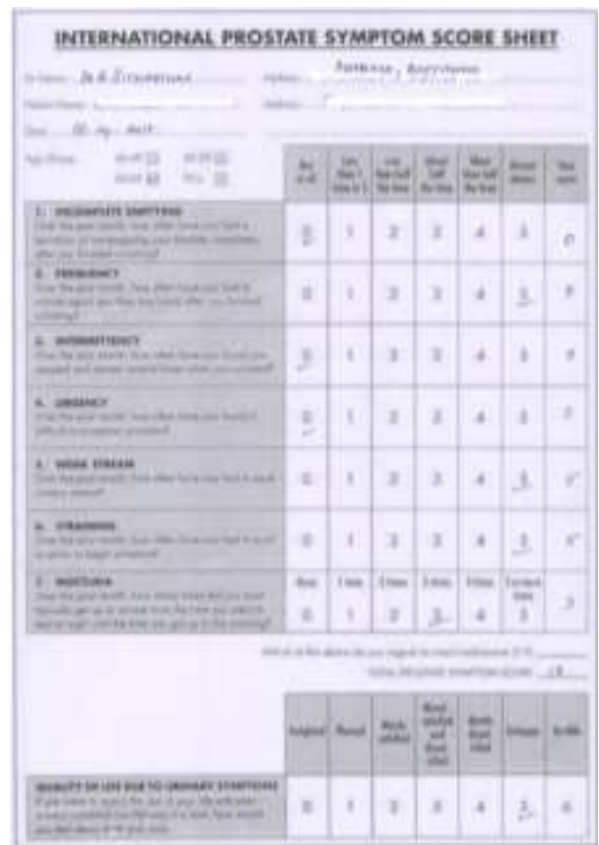

Fig 2: International Prostatic Symptom Score (IPSS).Before Treatment(Case No:1)

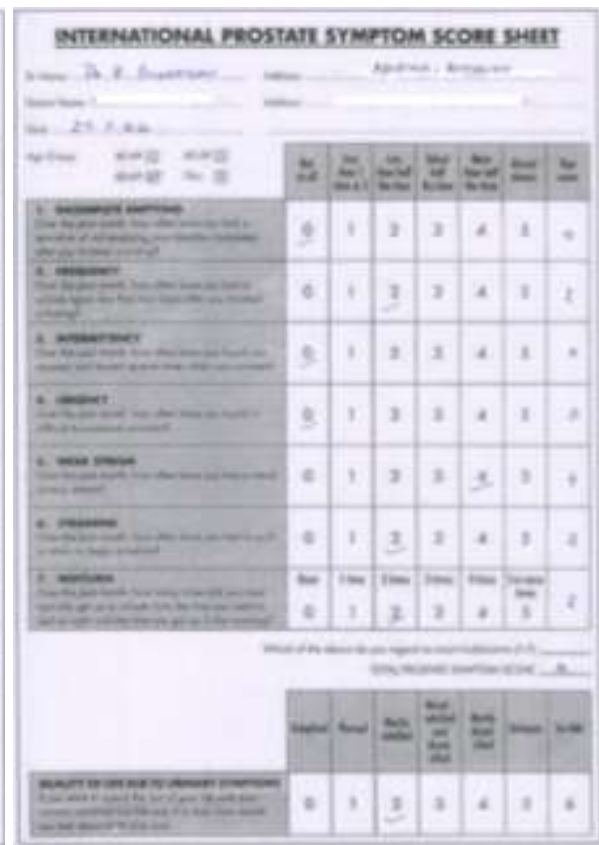

Fig 3: International Prostatic Symptom Score (IPSS). After Treatment(Case No:1) 


\begin{tabular}{|c|c|c|}
\hline Date & Follow up & Medicines \\
\hline $18-04-019$ & Pain while urinating sneezing on rainy weather & Rhus tox-200/6 doses-2 dose in a week. \\
\hline $18-05-019$ & Pain while urinating got reduced than before & Sac lac-6 doses \\
\hline $29-06-019$ & Pain got relived. Sneezing got reduced itching of face and legs & Suc-6 doses \\
\hline $11-08-019$ & Urinary complaints: pain on passing urine -reduced itching of face and legs persists <evening, night. & Sulphur-200/4 doses-1 dose/week \\
\hline $11-12-019$ & Urinary complaints-burning on micturition got reduced itching of skin -persists & Sulphur-200/4 doses-1 dose/week. \\
\hline $15-02-020$ & Itching with blackish discolouration of face and lower limbs urinary complaints-relieved & Sulphur 200/4 doses-1 dose/week \\
\hline $15-02-020$ & Itching with blackish discolouration of face and lower limbs urinary complaints-relieved & Rumex-30/6 doses (acute prescription) \\
\hline $21-03-020$ & Had cough with expectoration<early morning, wakes him up from sleep & Nux vom-200/4 doses 1 dose /week. \\
\hline $21-05-020$ & Urinary complaints-frequent desire to pass urine, frequent desire to pass stool-3-4 times /day & Nux vom 200/4 doses 1 dose/week. \\
\hline $27-07-020$ & Had cough with profuse expectoration<4am frequent urge to pass urine<night &
\end{tabular}

\section{Case-2}

Patient aged 56 years complained of hesitancy with burning during micturition, urine slow stream with interrupted flow, increased frequency especially at night since 7 months. Slowly he developed difficulty to hold urine. He has history of hypothyroidism since 15 years and on Thyronorm tablets on alternate days since 15 years. He is diabetic since 2 years with a maternal and paternal diabetic history. He has good appetite with increased thirst associated with dryness of mouth. Desires fish and intolerance to shell fishes. Stools are hard and unsatisfied, incomplete sensation with occasional bleeding after defecation. Sweat profuse all over body. Thermally hot. Heartburn occurs when food is not taken in time. Initially the patient was given Bryonia on considering the acute totality; later considering the constitutional totality Lycopodium was prescribed (Figure 4).

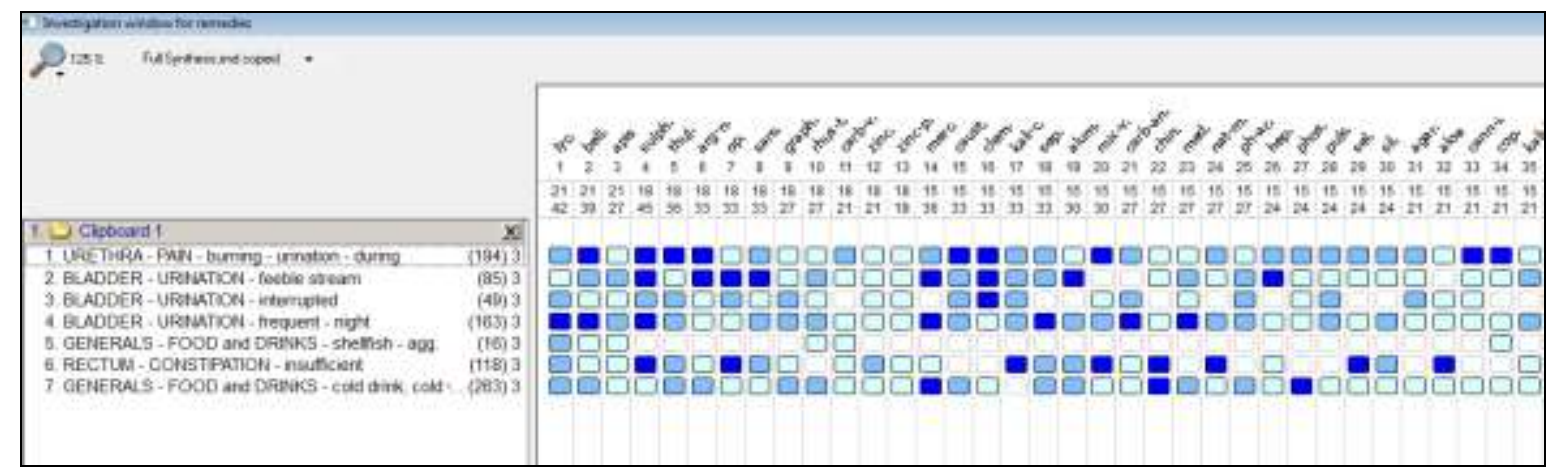

Fig 4: Repertory chart (Case No:2)

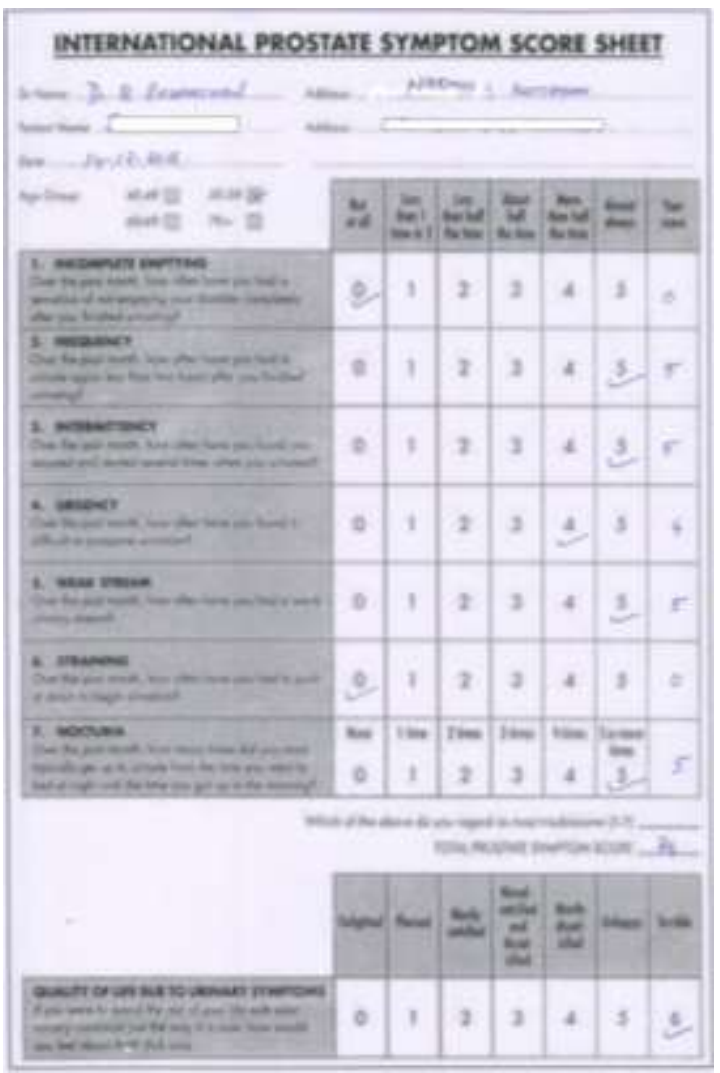

Fig 5: International Prostatic Symptom Score (IPSS).Before Treatment(Case No:2)

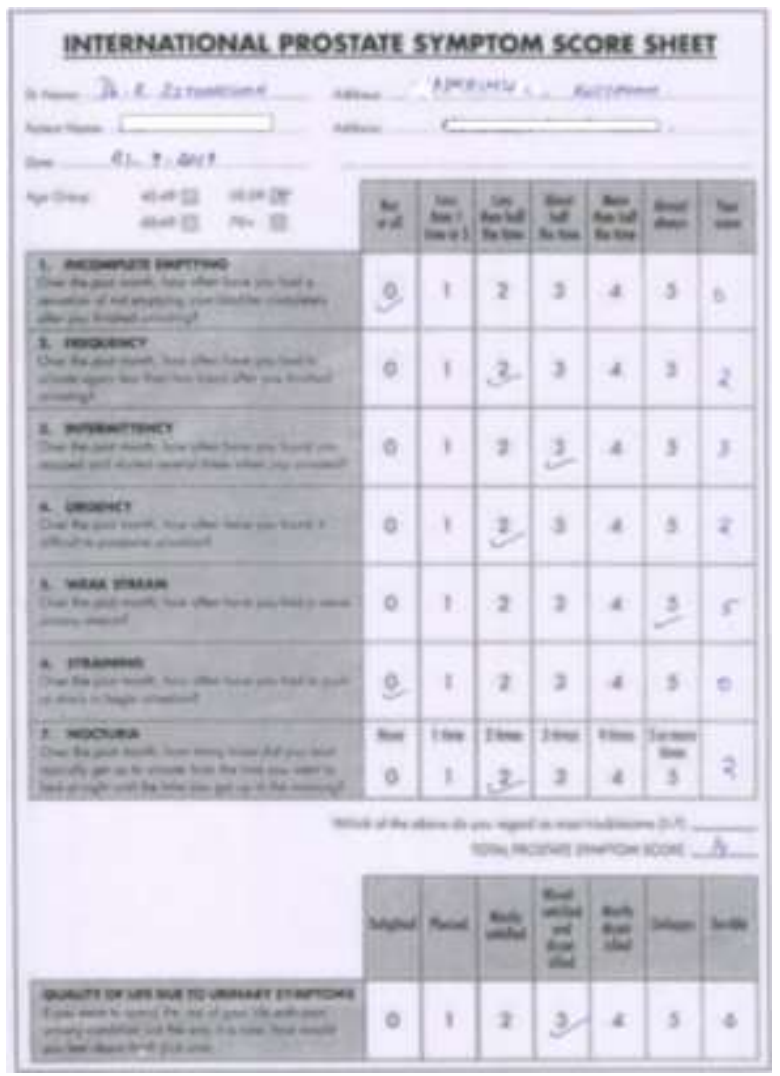

Fig 6: International Prostatic Symptom Score (IPSS). After Treatment(Case No:2) 


\begin{tabular}{|c|c|c|}
\hline Date & Follow-up & Medicines \\
\hline 14-12-2018 & $\begin{array}{c}\text { Burning on micturition, stream and hesitancy. stools difficult with incomplete sensation thirst- } \\
\text { increased }\end{array}$ & $\begin{array}{l}\text { Bryonia-200/4 doses } \\
\text { 1dose/week. }\end{array}$ \\
\hline 14-01-2019 & $\begin{array}{c}\text { Hesitancy persists, burning during urination -reduced. frequency of urination -reduced. Cough, } \\
\text { with scanty expextoration <night. Stools-difficult, hard, unsatisfactory. }\end{array}$ & $\begin{array}{c}\text { Bryonia 200/4 doses } 1 \\
\text { dose/week }\end{array}$ \\
\hline 25-02-2019 & $\begin{array}{c}\text { Hesitancy persists. Burning during micturition reduced. Headache <morning on } \\
\text { waking.Generals-stool-difficult to pass. Sleep-good }\end{array}$ & $\begin{array}{l}\text { Sac Lac -4 doses. } 1 \text { dose } \\
\text { /week. }\end{array}$ \\
\hline 18-04-2019 & $\begin{array}{l}\begin{array}{l}\text { Constipation persists. Hesitancy, with slow stream. Burning on micturition. Had distension of } \\
\text { abdomen with flatulence. }\end{array} \\
\end{array}$ & $\begin{array}{c}\begin{array}{c}\text { Lycopodium 200-4 doses. } 1 \\
\text { dose/week }\end{array} \\
\end{array}$ \\
\hline 20-06-2019 & $\begin{array}{c}\text { Hesitancy got reduced. slow stream of urine. Burning got reduced Distension of abdomen - } \\
\text { reduced. Constipation reduced. }\end{array}$ & $\begin{array}{l}\text { Sac lac }-4 \text { doses. } 1 \text { dose } \\
\text { /week }\end{array}$ \\
\hline 20-07-2019 & $\begin{array}{l}\text { Burning micturition -reduced. hesitancy got reduced. slow stream of urine. Distension of } \\
\text { abdomen - got reduced. Constipation -reduced }\end{array}$ & $\begin{array}{l}\text { Sac lac-4 doses } 1 \text { dose } \\
\text { /week }\end{array}$ \\
\hline 21-09-2019 & Burning micturation on and off hesitancy >; distension present; Flatulence; bowels- moderate; & $\begin{array}{l}\text { Lycopodium } 1 \mathrm{M} / 2 \text { dose. } \\
15 \text { days once } / 1 \text { dose. }\end{array}$ \\
\hline
\end{tabular}

\section{Case-3}

Patient aged 63 yrs complained of incontinence of urine, especially after drinking water, cold weather. Passes few drops of urine involuntarily before reaching the toilet. Patient was on conventional treatment since one year.
Family history of Diabetes. Fullness of stomach after eating food. Thirst reduced. Desires alcoholic drinks. He used to have difficult evacuation when moving away from home. Hot patient. PSA was $2.35 \mathrm{ng} / \mathrm{ml}$. Lycopodium was given after repertorization (Figure 7).

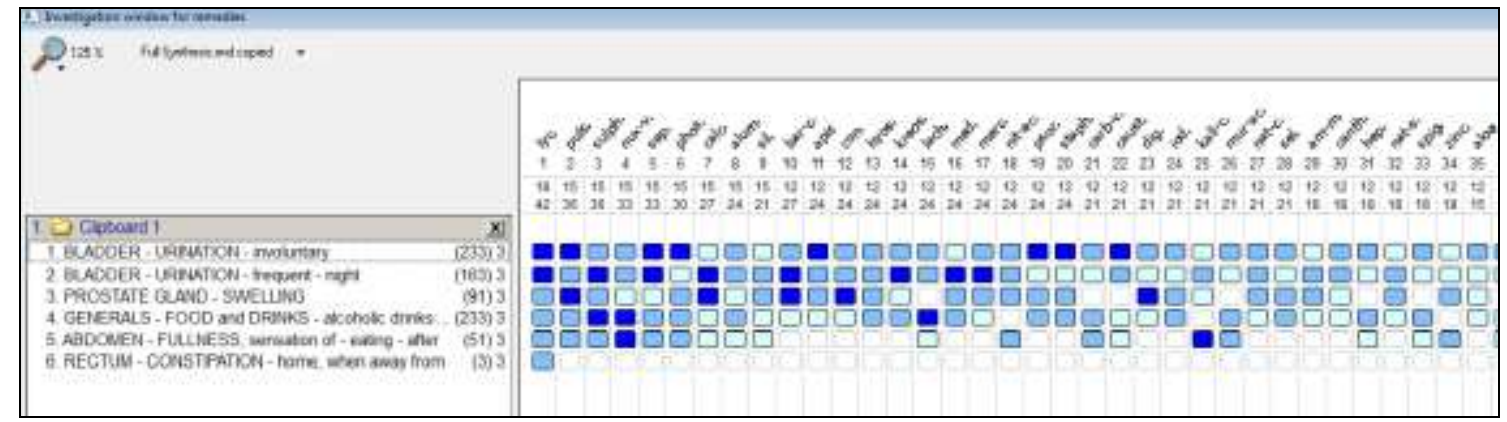

Fig 7: Repertory chart (Case No:3)

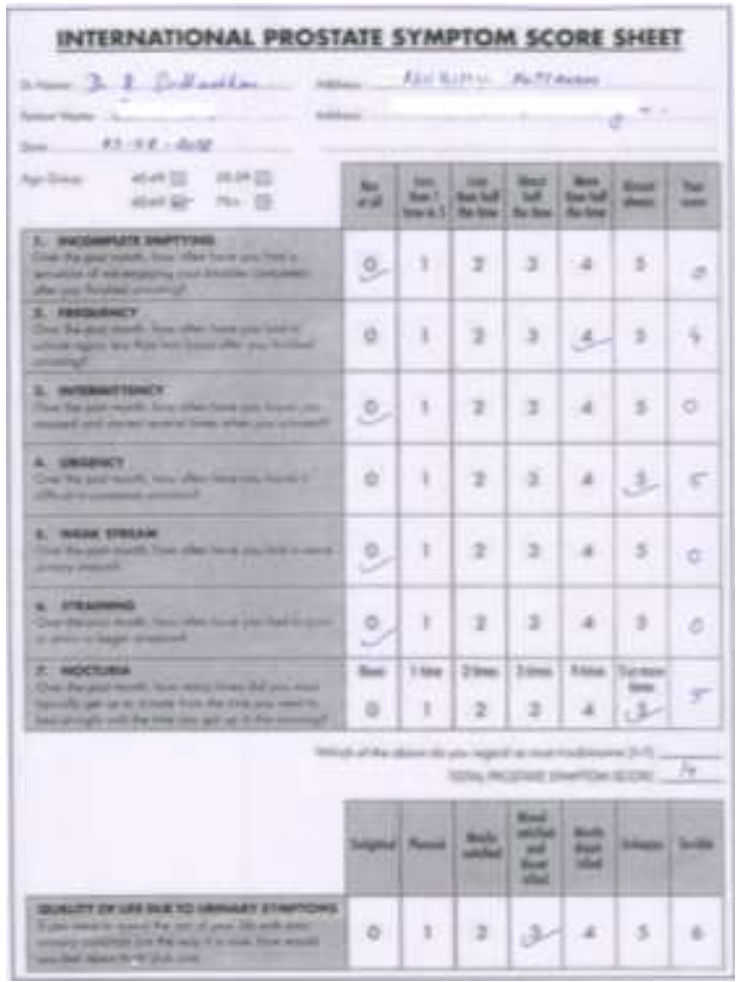

Fig 8: International Prostatic Symptom Score (IPSS).Before Treatment(Case No:3)

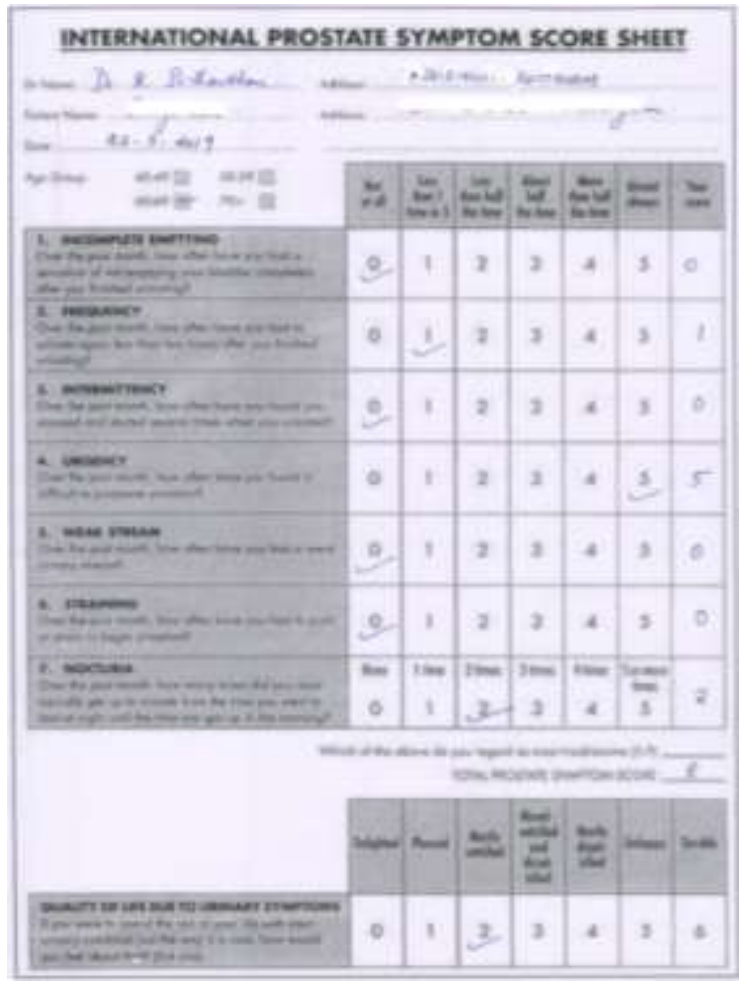

Fig 9: International Prostatic Symptom Score (IPSS). After Treatment(Case No:3) 


\begin{tabular}{|c|c|c|}
\hline Date & Follow-up & Medicine \\
\hline 03-08-2018 & $\begin{array}{c}\text { Involuntary urination. Frequency reduced, passage of urine in drops, Incomplete } \\
\text { emptying-persists. fullness of abdomen reduced. }\end{array}$ & $\begin{array}{c}\text { Lycopodium -30/4 doses. 1 } \\
\text { dose/week. }\end{array}$ \\
\hline 17-09-2018 & $\begin{array}{c}\text { Incontinence of urine. Increased urging to urination <night. Gastric disturbance <after } \\
\text { eating. }\end{array}$ & $\begin{array}{c}\text { Lycopodium 200/4 doses. 1 } \\
\text { dose/week. }\end{array}$ \\
\hline 08-10-2018 & $\begin{array}{c}\text { increased urging to urinate <night -reduced. Incomplete emptying. Incontinence persists, } \\
\text { passes in drops }\end{array}$ & $\begin{array}{c}\text { Lycopodium 200/4 doses } 1 \\
\text { dose/week. }\end{array}$ \\
\hline 07-11-2018 & difficulty in urination >. incontinence persists, passes in drops. fullness of abdomen \\
reduced. & $\begin{array}{c}\text { Lycopodium 1M/2 doses } 1 \text { dose } \\
\text { in } 15 \text { days. }\end{array}$ \\
\hline 10-12-2018 & Involuntary urination -got reduced. Frequency got reduced fullness of abdomen-reduced. & $\begin{array}{c}\text { Lycopodium 1M/2 doses } 1 \text { dose } \\
\text { in } 15 \text { days. }\end{array}$ \\
\hline $16-02-2019$ & Difficulty in urination relieved. No distension of abdomen & Sac Lac/ 4 doses. 1 dose /week \\
\hline 22-03-2019 & Urinary complaints got reduced than before. Generals better. & Sac lac -4 doses. 1 dose /week \\
\hline
\end{tabular}

\section{Discussion}

Homoeopathic system of medicine has lots to offer especially where surgical intervention is the primary choice of treatment. Homoeopathic therapeutics may be useful in cases where absolute surgical intervention is not warranted. Cases presented in this study were enrolled from Practice of Medicine OPD unit. All the three were diagnosed cases of BPH. In the first case Nux vomica is indicated. As acute prescriptions, Rhustox, Sulphur and Rumex had been prescribed as per need of patient, then finally Nux vomica had been prescribed on constitutional basis. Initially IPSS score at baseline was 18 (moderate) which got reduced to 10 (Figure 2\&3). The frequency of urination, nocturia was markedly improved. Straining while urination was reduced from the baseline score. Also the patient experienced significant improvement in QoL. In the second case according to the acute totality Bryonia was prescribed. Later as a constitutional remedy Lycopodium was given. Nocturia, frequency, postponding of urination was improved which helped to improve the QoL of the patient (Figure 5\&6). The third case presented with increased frequency with nocturia and showed an IPSS score of 14(moderate) at baseline which got reduced to 8(moderate) post interventionally (Figure 8\&9). In this case Lycopodium is given as it is indicated. The patient had involuntary dribbling which was not changed after medication. So a significant change in QoL was not observed.

\section{Conclusion}

BPH though being a surgical condition, homoeopathy has been successful in showing significant potentiality in the treatment and management of its obstructive and irritative symptomatology. This has widened the scope of Homoeopathy in the management of such conditions.

\section{Author's Contribution}

All authors contributed to writing the manuscript and each approved the final version.

\section{Funding}

None

\section{Conflict of Interest}

None declared.

\section{References}

1. Sugimura Y. Epidemiology and natural history of benign prostatic hyperplasia. Nihon rinsho. Japanese journal of clinical medicine 2002;60:318-21.

2. McNeal JG. The prostate gland: morphology and pathobiology. Monogr Urol 1983;4:3-33.

3. Girman C, Jacobsen S, Rhodes T, Guess H, Roberts R, Lieber M. Association of health-related quality of life and benign prostatic enlargement. European urology 1999;35(4):277-84.

4. Bid HK, Konwar R, Singh V. Benign prostatic hyperplasia: Is it a growing public health concern for India? Indian journal of medical sciences 2008;62(9):375-6.

5. Jepsen JV, Bruskewitz RC. Clinical manifestation and indications for treatment. In: Lepor H, editor. Prostatic Diseases. Philadelphia, PA: WB Saunders Co 2000, 123-142.

6. Girman CJ. Population-based studies of the epidemiology of benign prostatic hyperplasia. British journal of urology. Supplement 1998;82(1):34-43.

7. Asare GA, Afriyie D, Ngala RA, Appiah AA, Anang Y, Musah I, et al. Shrinkage of prostate and improved quality of life: management of $\mathrm{BPH}$ patients with croton membranaceus ethanolic root extract. EvidenceBased Complementary and Alternative Medicine 2015.

8. Ma CH, Lin WL, Lui SL, Cai XY, Wong VT, Ziea E, et al. Efficacy and safety of Chinese herbal medicine for benign prostatic hyperplasia: systematic review of randomized controlled trials. Asian Journal of Andrology 2013;15(4):471.

9. Zegarra L, Vaisberg A, Loza C, Aguirre RL, Campos M, Fernandez I, Talla O, Villegas L. Double-blind randomized placebo-controlled study of Bixa orellana in patients with lower urinary tract symptoms associated to benign prostatic hyperplasia. International braz j urol 2007;33:493-501.

10. Shukla GN, Nayak M, Kulkarni KS. Use of PR-2000, a herbal formulation in the medical management of benign prostatic hyperplasia. Indian Journal of Clinical Practice 2002;13(2):53-6.

11. Oberai P, Roja V, Ramesh D, et al. Homoeopathic medicines in the management of benign prostatic hyperplasia: a multicentric prospect. Indian $\mathrm{J}$ Res Homoeopath 2012;6:16-5

12. Gupta G, Singh JP, Tandon S, et al. Evidence based clinical study to assess the usefulness of homoeopathic medicines in patients of benign prostatic hyperplasia. Indian J Res Homoeopath 2010;4:49-6

13. Hati AK, Paital B, Naik KN, Mishra AK, Chainy GB, Nanda LK. Constitutional, organopathic and combined homeopathic treatment of benign prostatic hypertrophy: a clinical trial. Homeopathy 2012;101(04):217-223

14. Reddy GRC, Oberai P, Singh V, Nayak C. Treating benign prostatic hyperplasia in elderly men with homoeopathy: a series of eleven cases. Indian J Res Homoeopath 2009;3:37-39

15. Macdiarmid SA, Goodson TC, Holmes TM, Martin PR, Doyle RB. An assessment of the comprehension of the American Urological Association Symptom Index. The Journal of urology 1998;159(3):873-4. 